\title{
Pembuatan Pupuk Kompos Di Dayah Sirajul Sirajul Huda Al-Aziziyah Kabupaten Pidie Jaya, Aceh
}

\author{
Halus Satriawan*, Hakim Muttaqiem, Najmuddin \\ Universitas Almuslim, Jalan Almuslim, Matangglumpangdua, Paya Cut, Peusangan, \\ Kabupaten Bireuen, Aceh 24261, Indonesia \\ ${ }^{*}$ Corresponding author email: halussatriawan@umuslim.ac.id
}

\section{Diterima: April 2019; Revisi: April 2019; Diterbitkan: Mei 2019}

\begin{abstract}
Abstrak
Kegiatan pengabdian kepada masyarakat dalam bentuk penyuluhan dan pelatihan ini bertujuan untuk membantu santri dan guru di Dayah Sirajul Huda Al-Aziziyah Desa Blang Awe Kecamatan Meuredu Kabupaten Pidie Jaya Provinsi Aceh. Kegiatan ini selama 14 hari dimulai sejak Sabtu, 20 Juli 2019 - 3 Agustus 2019. Alat yang dibutuhkan dalam proses pembuatan pupuk kompos ini adalah parang, timbangan, ember, pengukur suhu dan $\mathrm{pH}$ Tanah, terpal, talenan, kantong plastik (kresek), karung, tali. Sedangkan bahan yang digunakan jerami padi, kulit buah-buahan, kotoran ternak Sapi, EM-4, kapur dolomite, gula pasir dan air. Metode pengomposan dilakukan dengan menggunakan fermentasi (anaerob). Adapun parameter pengamatan dari kegiatan ini adalah kecepatan fermentasi dari penggunaan EM-4 sebagai dekomposer terhadap bahan-bahan yang digunakan. Hasil pengomposan pupuk kompos dibuat dengan proses pengomposan menggunakan EM-4. Penggunaan EM-4 dapat menghasilkan pupuk organik dalam waktu yang lebih cepat dibandingkan dengan cara konvensional, yaitu selama 2 minggu. Dampak pada mitra yakni 1) adanya pemahaman secara teori dan praktik tentang proses pengolahan limbah organik menjadi pupuk kompos, dan 2) adanya keterampilan dalam pengolahan limbah organik (limbah pertanian dan ternak) menjadi kompos organik yang dapat dimanfaatkan dalam budidaya tanaman.
\end{abstract}

Kata Kunci: Limbah Organik; Pupuk Kompos; EM4

\section{Making Compost at Dayah Sirajul Sirajul Huda Al-Aziziyah, Pidie Jaya Regency, Aceh}

\begin{abstract}
This community service activity in the form of counseling and training aims to help students and teachers at Dayah Sirajul Huda Al-Aziziyah, Blang Awe Village, Meuredu District, Pidie Jaya Regency, Aceh Province. This activity lasted for 14 days starting from Saturday, July 202019 - August 3, 2019. The tools needed in the compost-making process are machetes, scales, buckets, temperature and $\mathrm{pH}$ gauges, tarpaulins, cutting boards, plastic bags (kresek), sacks., rope. While the materials used are rice straw, fruit skins, cow manure, EM-4, dolomite lime, sugar and water. The composting method is carried out using fermentation (an-aerobic). The observation parameter of this activity is the fermentation speed of using EM-4 as a decomposer for the materials used. The results of composting compost made by composting using EM-4. The use of EM-4 can produce organic fertilizers in a faster time than conventional methods, namely for 2 weeks. The impact on partners is 1) theoretical and practical understanding of the process of processing organic waste into compost, and 2) skills in processing organic waste (agricultural and livestock waste) into organic compost that can be used in plant cultivation.
\end{abstract}

Keywords: Organic Waste; Compost; EM4

How to Cite: Satriawan, H., Muttaqiem, H., \& Najmuddin, N. (2019). Pembuatan Pupuk Kompos Di Dayah Sirajul Huda Al-Aziziyah Kabupaten Pidie Jaya, Aceh. Lumbung Inovasi: Jurnal Pengabdian kepada Masyarakat, 4(1), 31-35. doi:https://doi.org/10.36312/linov.v4i1.441 


\section{PENDAHULUAN}

Keberlangsungan lembaga pendidikan seperti Dayah Sirajul Huda "Al-Aziziyah tidak bergantung pada dana pemerintahan. Lembaga pendidikan islam dayah semuanya bersifat swasta, oleh karena itu diperlukan usaha mandiri dari pengelola dayah (pesantren) untuk menghasilkan pendapatan dan memenuhi kebutuhan santri dan guru. Berdasarkan hasil wawancara dengan pimpinan lembaga, Dayah sirajul Huda 'alAzizizyah merupakan milik masyarakat dalam kemukiman di Kecamatan Meureudu Kabupaten Pidie Jaya. Untuk keberlangsungan pendidikan di dayah ada sumbangan yang diberikan oleh masyarakat, dan sekarang dayah ini memiliki luas tanah perkebunan $0,5 \mathrm{ha}$, yang telah dimanfaatkan untuk menanam komoditas tanaman pangan. Hasil dari usaha ini digunakan untuk menggerakkan roda pendidikan di dayah ini.

Kendala yang dihadapi dalam proses budidaya tanaman di Dayah Sirajul Huda "alAziziyah adalah belum maksimalnya hasil panen. Menurut salah seorang dewan guru yang ikut mengelola lahan dayah untuk penanaman sayuran, hal ini disebabkan karena mereka belum memiliki kemampuan yang bagus dalam aspek budidaya, termasuk penerapan teknologi pemupukan. Padahal potensi sumberdaya lokal untuk menghasilkan pupuk organic sangat melimpah sehingga berpeluang dapat menurunkan biaya produksi, meningkatkan kualitas hasil dan meningkatkan keuntungan produksi dalam hal pemasaran produk.

Pupuk merupakan bagian penting dari pertanian sebagai material yang ditambahkan pada media tanam atau tanaman untuk mencukupi kebutuhan hara yang diperlukan oleh tanaman sehingga mampu berproduksi dengan baik. Secara sederhana kesuburan tanah dapat didefinisikan sebagai kemampuan tanah menyediakan unsur-unsur yang di perlukan oleh tanaman. Kesuburan tanah merupakan kunci dari sistem pertanian yang berkelanjutan, yaitu suatu praktek pertanian yang melibatkan pengelolaan sumberdaya alam (Handayanto et.al, 2017; Atmojo, 2003). Untuk meningkatkan kesuburan tanah bisa dengan menggunakan pupuk kompos (Hunaepi, dkk. 2018; Alex, 2013) pupuk kompos dapat memperbaiki struktur dan karakteristik tanah sehigga pertumbuhan tanaman dapat maksimal. Pupuk kompos adalah bahan organik yang dibusukkan pada suatu tempat yang terlindungi dari matahari dan hujan, diatur kelembabannya (Roidah, 2013). Manfaat menggunakan pupuk organik adalah dapat menjaga kesimbangan tanah karena tidak menggunakan pestisida kimia, bisa menjamin kesehatan produksi pertanian, dan dapat menghematkan biaya produksi (Roidah, 2013). Selain itu Hunaepi, Dharmawibawa \& Asy'ari (2018) menjelaskan bahwa pupuk kompos memiliki manfaat meningkatkan kemampuan tanah untuk menahan air, meningkatkan aktivitas biologi tanah, dan menyediakan unsur mikro bagi tanaman

Limbah pertanian merupakan sisa-sisa hasil pertanian yang berasal dari tumbuhan dan hewan ternak misalnya sisa dari pemanenan hasil tanaman pangan, perkebunan, hortikultura, sampah rumah tangga, kotoran hewan ternak dan sebagainya. Pemanfaatan limbah pertanian sangat perlu kita lakukan agar tidak terjadi pencemaran lingkungan selain itu dapat dijadikan masukan atau tambahan bagi petani ataupun masyarakat yang memanfaatkan limbah tersebut. Masyarakat telah menyadari bahwa menggunakan bahanbahan kimia non alami seperti pupuk dan pestisida sintetik serta hormon tumbuhan dalam memproduksi hasil pertanian ternyata menimbulkan efek terhadap kesehatan manusia dan lingkungan. Gaya hidup sehat menjadi trend bagi masyarakat dunia dan kini telah melembaga secara internasional yang diwujudkan melalui regulasi perdagangan global, makanan yang dikonsumsi mempunyai kandungan nutrisi tinggi dan ramah lingkungan.

Adapun tujuan pelaksanaan kegiatan pengabdian masyarakat tentang pembuatan pupuk kompos adalah untuk memberikan pengetahuan praktis kepada santri dan guru di Dayah Sirajul Huda Al-Aziziyah dalam memanfaatkan limbah pertanian dan peternakan untuk menjadi produk yang bermanfaat di bidang pertanian seperti pupuk kompos.

\section{METODE PELAKSANAAN}

Pelatihan pembuatan pupuk kompos dilakasanakn di di Dayah Sirajul Huda Al-Aziziyah Desa Blang Awe Kecamatan Meuredu Kabupaten Pidie Jaya Provinsi Aceh. Metode yang digunakan dalam kegiatan pemberdayaan masyarakat ini adalah PRA (Participatori Rural Appraisal) dalam pelaksanaannya melibatkan mitra dalam seluruh kegiatan dan stakeholders. Penggunaan metode ini bertujuan agar mitra dapat saling berbagi, meningkatkan, dan 
menganalisi pengetahaun mereka tentang kondisi dan kehidupan masyarakat, membuat rencana dan bertindak (Hunaepi, dkk. 2018). Kegiatan ini selama 14 hari dimulai sejak Sabtu, 20 Juli 2019 - 3 Agustus 2019. Alat yang dibutuhkan dalam proses pembuatan pupuk kompos ini parang, timbangan, ember, pengukur suhu dan $\mathrm{pH}$ Tanah, terpal, talenan, kantong plastik (kresek), karung, tali. Sedangkan bahan yang digunakan jerami padi, kulit buahbuahan, kotoran ternak Sapi, EM-4, kapur dolomite, gula pasir dan air.

Langkah kerja pembuatan pupuk kompos sebagai berikut:

1. Persiapan alat dan bahan yang dibutuhkan dalam pelaksanaan kegiatan, yaitu jerami padi 5 karung, kotoran sapi kering 1 karung, kapur dolomit 5 kg, gula pasir $1 \mathrm{~kg}$ dan EM4 1 liter.

2. Jerami padi dipotong-potong menjadi ukuran yang kecil $( \pm 10-15 \mathrm{~cm})$, pemotongan jerami ini dimaksudkan untuk mempermudah pencampuran bahan yang lain dan mempercepat penguraian bahan

3. jerami yang telah dipotong dan dipersiapkan dihamparkan di atas terpal, kemudian di taburkan kotoran sapi yang sudah kering, selanjutnya ditambahkan kapur dolomite kemudian diaduk-aduk

4. Setelah tercampur merata, pada campuran jerami, kotoran sapi dan kapur dolomit kemudian disiram larutan air, EM4 dan gula pasir secukupnya, yaitu ditandai dengan jika bahan kompos diperas, terasa airnya namun tidak sampai menetes.

5. Bahan yang sudah tercampur kemudian ditutup rapat menggunakan terpal, tanpa meninggalkan lubang yang berpotensi menghasilkan kondisi aerobik.

6. Selanjutnya dilakukan pengukuran suhu dan $\mathrm{pH}$ tanah setiap 7 hari dengan menggunakan pengukur suhu dan $\mathrm{pH}$ tanah dan pengamatan berlangsung selama 2-3 minggu. Suhu bahan dipertahankan pada suhu maksimal 40oC.

7. Setelah 16 hari proses pengomposan pupuk kompos selesai, ditandai dengan perubahan bentuk bahan yang tadinya berupa jerami dan lainnya, menjadi bahan yang sudah melapuk dengan warna bahan hitam seperti tanah hutan dan remah, dengan $\mathrm{pH}$ netral.

\section{HASIL DAN PEMBAHASAN}

Pengomposan adalah proses di mana bahan organik mengalami penguraian secara biologis, khususnya oleh mikrobamikroba yang memanfaatkan bahan organik sebagai sumber energi (Hunaepi, dkk. 2018). Proses pembuatan pupuk kompos dengan bahan limbah pertanian dan kotoran ternak dilakukan menggunakan metode anaerob dengan menggunakan stater EM4. Metode anaerob merupakan proses pengomposan yang tidak memerlukan ketersedian oksigen, namun hanaya membutuhkan tambahan panas dari luar. Sedangkan untuk mempercepat proses dekomposisi oleh bakteri dalam proses pengomposan ditambahkan dengan EM4. EM4 atau Effective Microorganism 4 yang merupakan kultur campuran dari mikroorganisme hidup yang sangat menguntungkan bagi kesuburan tanah, dan bermanfaat bagi pertumbuhan tanaman.

Untuk mempercepat pengoposan limbah maka limbah pertanian berupa jerami dipotong kecil-kecil dengan ukuran 5-10cm. setelah itu Agar komponen unsur dalam pupuk kompos terpenuhi, maka dalam dalam pembuatan pupuk kompos dengan jermai ditambambahkan dengan kotoran ternak (sampi) dan dolomit.

Kegiatan dilakukan langsung oleh semua anggota mitra didampingi oleh tim pengabdian. adapaun proses pembuatannya disajikan pada berikut ini.

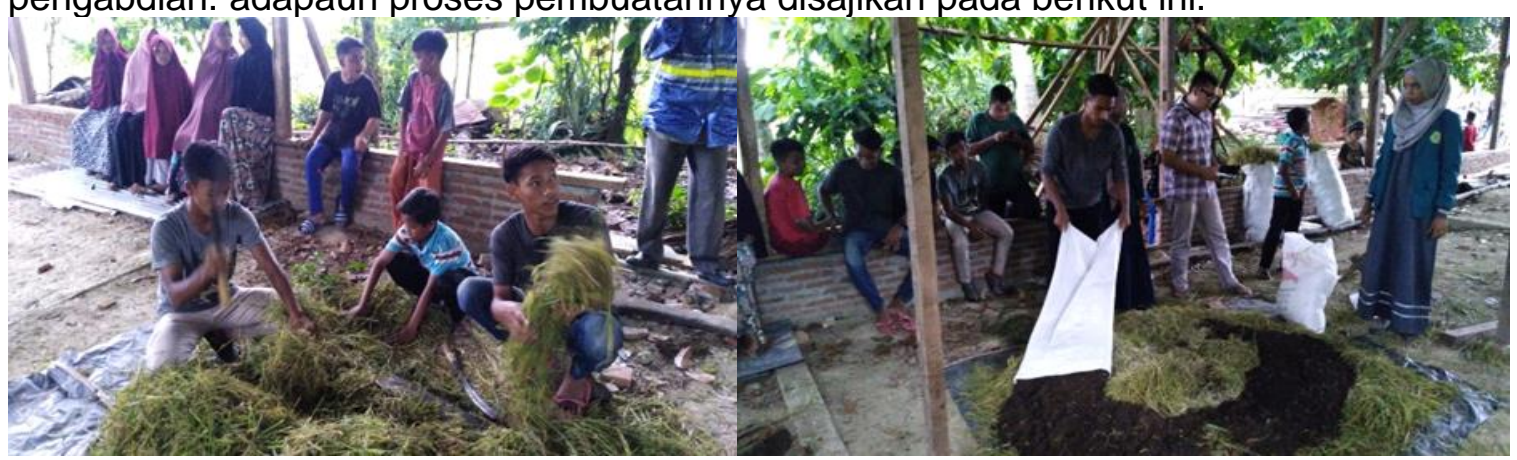

Gambar 1. Proses mencacah/pemotongan jerami dan proses pencampuran dengan kotoran ternak dan dolomit 
Proses pembuatan kompos dengan memamnfaatnkan limbah pertanian dan kotoran ternak dengan tahapan sebagai berikit;.

1. Siapkan alat dan bahan yang dibutuhkan selama proses pengomposan

2. Siapkan bahan organik yang akan dikomposkan berupa jermai padi, dan kotoran ternak

3. Siapkan dekomposer (EM4) sebagai starter. Caranya, campurkan 1 cc EM4 dengan 1 liter air dan 1 gram gula. Kemudian diamkan selama 24 jam

4. Ambil terpal plastik sebagai alas, simpan bahan organik yang sudah dirajang halus di atas terpal. Campurkan dengan kotoran ternak. Kemudian semprotkan larutan EM4 yang telah diencerkan tadi. Aduk sampai merata, jaga kelembaban pada kisaran 30-40\%, apabila kurang lembab bisa disemprotkan air.

5. Tutup terpal sampai tidak ada udara yang masuk. Pertahankan kondisi suhu pada saat fermentasi akan berkisar $35-45^{\circ} \mathrm{C}$

6. Setelah empat hari cek kematangan kompos. Pupuk kompos yang matang dicirikan dengan baunya yang tidak menyengat

Pengamatan pertama tanggal 27 Juli 2019 menghasilkan sudah mulai adanya perubahan dan proses penguraian, ditandai dengan munculnya jamur dan perubahan warna bahan yang semula hijau menjadi kuning kecokelatan (Gambar 2).

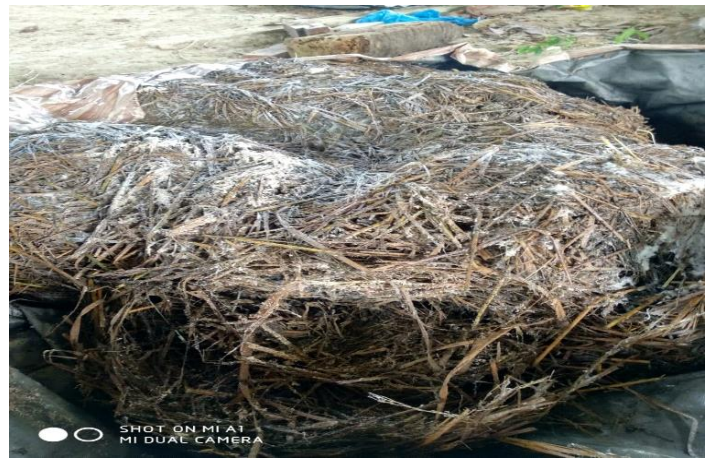

Gambar 2. Proses pengomposan hari ke -7 atau pengamatan pertama.

Perubahan warna pada kompos akibat dari adanya aktivitas mikroba dekomposer. dekomposer merupakan organisme yang memakan organisme mati dan produk-produk limbah dari organisme lain. Pengurai membantu siklus nutrisi kembali ke ekosistem lainnya. Dekomposer membuat tanah kaya dengan menambahkan senyawa organik dengan itu. Zat seperti karbon, air dan nitrogen dikembalikan ke ekosistem melalui tindakan pengurai. Yang termasuk contoh pengurai (dekomposer) adalah serangga, cacing tanah, bakteri, jamur, belatung, lactobacteria, kecoa, ragi, siput, lumut, dan actinomycetes (Wikipedia, 2020).

Tumbuhnya spora jamur pada bahan yang dikomposkan menandakan telah dimulainya proses fermentasi yang intensif. Jamur diketahui merupakan mikroorganisme yang sangat cepat merobak bahan selulosa dan lignin dari tanaman menjadi bahan yang lebih sederhana yaitu bahan dari senyawa organic (humus).

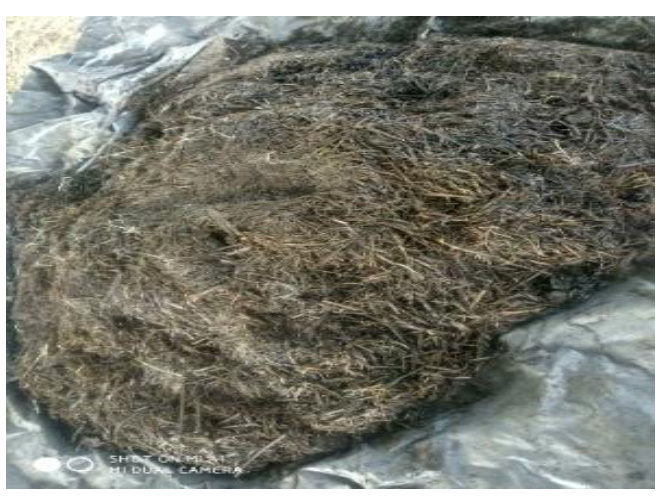

Gambar 3. Pengamatan kompos minggu ke-2 (hari ke-14) 
Proses pengomposan pada hari ke 14 telah menghasilkan perubahan struktur dan warna bahan kompos. Pada pengamatan ini, bahan kompos telah mengalami pelapukan yang intensif, ditandai dengan mudahnya bahan kompos hancur jika diremas dan ukuran bahan sudah mulai menyusut serta warna telah mulai menghitam.

Proses pembuatan kompos organik dilakukan oleh semua anggota mitra yang didampigi oleh tim PkM. Kegiatan berjalan dengan lancar sesuai dengan perencanaan yang telah dibuat bersama. Adapun dampak dari kegitan ini adalah mitra memahami secara teori dan praktik proses pembuatan pupuk organik dengan memanfaatakan limbah pertanian dan ternak.

\section{KESIMPULAN}

Kegiatan PkM yang dilakukan telah memberikan dampak yang baik untuk mitra di Dayah Sirajul Sirajul Huda Al-Aziziyah Kabupaten Pidie Jaya, Aceh. Adapun dampak tersebut adalah 1) adanya pemahaman secara teori dan praktik tentang proses pengolahan limbah organik menjadi pupuk kompos, dan 2) adanya keterampilan dalam pengolahan limbah organik (limbah pertanian dan ternak) menjadi kompos organik yang dapat dimanfaatkan dalam budidaya tanaman.

\section{REKOMENDASI}

Sebagai saran diperlukan upaya pendampingan lebih lanjut oleh penyuluh pertanian kepada para petani, agar keterampilan mereka semakin meningkat serta dapat memanfaatkan teknologi pengomposan pupuk kompos dengan baik untuk meningkatkan hasil usah ataninya.

\section{DAFTAR PUSTAKA}

Atmojo, S.W., Peranan bahan organik terhadap kesuburan tanah dan upaya pengelolaannya. Pidato Pengukuhan Guru Besar Ilmu Kesuburan Tanah. Fakultas Pertanian, Universitas Sebelas Maret, Surakarta, 2003.

Alex S., 2013. Sukses Mengolah Sampah Organik menjadi pupuk organic. Yogyakarta; Pustaka Baru Press.

Handayanto, E., N. Muddarisna, and A. Fiqri, Pengelolaan Kesuburan Tanah. 2017: Universitas Brawijaya Press.

Hunaepi, Dharmawibawa I.D., Samsuri, T., Mirawati, B., \& Asy'ari, M. (2018). Pengolahan Limbah Baglog Jamur Tiram Menjadi Pupuk Organik Komersil. Jurnal SOLMA. 7(2), 277-288. Doi:http://dx.doi.org/10.29405/solma.v7i2.1392.

Hunaepi, Dharmawibawa D.I., \& Asy'ari M. (2018) Pemberdayaan Kelompok Budidaya Jamur Tiram Dalam Pemanfaatan Limbah Baglog Menjadi Pupuk Organik. Proceding Seminar Nasional dan Diskusi Panel Multidisiplin Hasil Penelitian \& Pengabdian kepada $\begin{array}{llll}\text { Masyarakat, } & \text { Jakarta, } & 2 & \text { Agustus }\end{array}$ http://www.proceeding.unindra.ac.id/index.php/dispanas2018/article/view/21

Hunaepi, Dharmawibawa D.I., \& Asy'ari M. (2018) mengolah limbah baglog jamur menjadi pupuk organik. Mataram. Duta Pustaka Ilmu. https://www.researchgate.net/publication/335569202 MENGOLAH LIMBAH BAGLO G JAMUR MENJADI PUPUK ORGANIK

Higa, T. and G.N. Wididana 199lb. Changes In the soil microflora Induced by effective microorganisms. p.153-162. In J.F. Parr, S.B. Hornick, and C.E. Whitman (ed.) Proceedings of the First International Conference on Kyusei Nature Farming. U.S. Department of Agriculture, Washington, D.C., USA.

Roidah, I.S., Manfaat penggunaan pupuk organik untuk kesuburan tanah. Jurnal BONOROWO, 2013. 1(1): p. 30-43.

Wikipedia, (2020) Pengurai. https://id.wikipedia.org/wiki/Pengurai 